\title{
Características produtivas, agronômicas e nutricionais do capim-tanzânia em cinco diferentes idades ao corte
}

\author{
[Productivity, agronomical and nutritional traits of Tanzânia grass cut on five different ages] \\ G.H.F. Castro ${ }^{1}$, N.M. Rodriguez ${ }^{1}$, L.C. Gonçalves ${ }^{1}$, R.M. Maurício ${ }^{2}$ \\ ${ }^{1}$ Escola de Veterinária - UFMG \\ Caixa Postal 567 \\ 30123-970 - Belo Horizonte, MG \\ ${ }^{2}$ Universidade Federal de São João Del-Rei - São João Del-Rei, MG
}

\begin{abstract}
RESUMO
Avaliou-se o capim-tanzânia (Panicum maximum cv Tanzânia) cortado aos 42, 63, 84, 107 e 126 dias quanto à produtividade, às características agronômicas, à composição bromatológica e à digestibilidade in vitro. Observou-se aumento na altura da planta do capim-tanzânia até os 84 dias, com aumento da produção de massa verde de forragem e aumento na produção de matéria seca com o avançar da idade ao corte. $\mathrm{O}$ aumento da idade ao corte resultou em diminuição do percentual de folhas e em aumento no percentual de hastes. Na composição bromatológica, observaram-se diminuição do teor de proteína bruta e aumento das frações fibrosas, com aumento do nitrogênio retido nessa última com o avançar da idade. Os resultados obtidos refletiram-se na cinética de fermentação ruminal, descrita pela técnica in vitro semiautomática de produção de gases, demonstrando menor potencial de produção de gases, menor taxa fraccional de fermentação e, consequentemente, menor degradabilidade efetiva da matéria seca. Recomenda-se o corte do capim-tanzânia no intervalo de 42 a 63 dias de crescimento.
\end{abstract}

Palavras-chave: capim-tanzânia, Panicum maximum, composição bromatológica, produção de gases

\begin{abstract}
The potential for use of Tanzania grass (Panicum maximum cv. Tanzania) cut at different ages for the production of silage was evaluated. In the first experiment, Tanzania grass, cut at 42, 63, 84, 107, and 126 days of growth, was evaluated considering its productivity, agronomic characteristics and chemical composition. It was observed gain in height of Tanzania grass until the $84^{\text {th }}$ day, with increased the production of green fodder and mass production of dry material with the advancing age of cutting. It also resulted in a decrease in the percentage of leaves and an increase in the percentage of stems. Regarding chemical composition, it was detected a decrease in crude protein percentage and an increase of fibrous fractions with the advancing of age. The results were reflected in the kinetics of rumen fermentation of Tanzania grass cut on the $42^{\text {nd }}, 63^{\text {rd }}, 84^{\text {th }}, 107^{\text {th }}$, and $126^{\text {th }}$ days, described by semi-automated in vitro gas production technique, showing less potential for gas production, lower fractional of fermentation and, consequently, less effective degradability of dry matter. For the production of grass silage, it is recommended cutting the Tanzania grass from 42 to 63 days of age.
\end{abstract}

Keywords: Tanzania grass, Panicum maximum, bromatological composition, gas production

\section{INTRODUÇÃO}

Os sistemas de criação de ruminantes no Brasil têm na pastagem sua principal fonte de alimento. A produção das gramíneas tropicais pode ser

Recebido em 30 de agosto de 2009

Aceito em 3 de maio de 2010

E-mail: ghfcastro@ufmg.br

Apoio: FAPEMIG dividida em duas estações bem definidas: o período das águas, quando há grande disponibilidade de forrageiras com alta qualidade nutricional, e o período da seca, quando seu crescimento torna-se restrito devido às condições climáticas, com consequente redução na 
qualidade da forrageira. A escolha de alternativas que vise minimizar os efeitos da sazonalidade na produção de plantas forrageiras deve ser coerente com a estratégia de exploração pecuária, diferenciando-se em função do nível de intensificação do uso das pastagens.

Dessa forma, deve haver planejamento alimentar na tentativa de se ajustar o suprimento à demanda de forragem em todas as épocas, possibilitando, assim, a produção uniforme ao longo do ano.

O uso de pastagens em sistema contínuo, com o ajuste da taxa de lotação com base no período das águas, demanda alimentação suplementar durante o período seco. A situação agrava-se quando a forrageira utilizada é do gênero Panicum, que concentra a produção de matéria seca no verão, em torno de $87 \%$ da produção anual (Jank et al., 1997). Pedreira (1972) estimou que é necessária uma variação muito ampla, de 0,2 a 5,3UA/ha, na lotação animal, para ajustar o consumo de forragem à taxa de crescimento do capim-colonião (Panicum maximum) durante o ano. Todavia, devem ser considerados os aspectos relacionados à eficiência dos sistemas de colheita, processamento e conservação, assim como a qualidade da forragem produzida e os aspectos econômicos. A produção e a conservação de forragem de alto valor nutritivo são de extrema importância para garantir a continuidade da oferta de forragem durante $o$ período de escassez de pasto, permitindo aos animais plenas condições para exibirem seu potencial genético.

As técnicas in vitro têm sido utilizadas para a determinação do valor nutricional de alimentos, sendo os parâmetros obtidos neste tipo de avaliação relacionados ao consumo e à digestibilidade em ruminantes (Ørskov, 2002; Guimarães Jr. et al., 2008). A técnica in vitro semiautomática de produção de gases (Mauricio et al., 1999) tem a capacidade de avaliar grande número de substratos e descrever a cinética de fermentação ruminal. Esta tem sido utilizada em estudos de classificação de substratos com altos teores de carboidratos, em estudos de fermentabilidade de componentes específicos, na avaliação de fatores antinutricionais e na predição da energia metabolizável dos alimentos (Willians, 2003).
Este trabalho teve o objetivo de avaliar as características agronômicas, a composição bromatológica e a cinética de fermentação ruminal dos componentes nutricionais do capimtanzânia (Panicum maximum cv Tanzânia) colhido em cinco idades de corte e sugerir o momento ideal de sua utilização na alimentação de ruminantes.

\section{MATERIAL E MÉTODOS}

O experimento foi realizado na Fazenda Experimental São Judas Tadeu, pertencente à Fundação Ezequiel Dias, situada no município de Betim, MG, latitude $19,8782^{\circ} \mathrm{C}$, longitude $44,1896^{\circ} \mathrm{C}$, altitude $869,87 \mathrm{~m}$. Foi utilizada uma área já existente de Panicum maximum cv Tanzânia, dividida em quatro curvas em nível, sendo que em cada curva foram estabelecidos cinco piquetes com área de $600 \mathrm{~m}^{2}$ cada. A análise de solo apresentou as seguintes características: $\mathrm{pH} 5,8, \mathrm{Al}^{+}=3,02$ cmol.carga/dm $\mathrm{dm}^{3}, \mathrm{P}=2,4 \mathrm{mg} / \mathrm{dm}^{3}, \mathrm{~K}=122 \mathrm{mg} / \mathrm{dm}^{3}$ e índice de saturação de bases de 67,97\%. Inicialmente, foi feita a uniformização da área experimental com o uso de roçadeira mecânica. Para a adubação de cobertura, foram utilizados $200 \mathrm{~kg} / \mathrm{ha}$ de superfosfato simples, em aplicação única, e 400kg/ha de adubo N:P:K 20-05-20, divididos em duas aplicações. Foi avaliado o capim-tanzânia cortado aos 42, 63, 84, 107 e 126 dias. Em cada curva de nível, foi estabelecido um piquete de cada idade avaliada, havendo quatro repetições para todos os tratamentos.

Foi avaliada a altura média das plantas (ALT), a produção de massa de forragem verde total (PMVT), a produção de matéria seca por hectare (PMS), o percentual de folhas (FMS), o percentual de hastes (HMS) e o percentual de matéria morta na matéria seca (MMMS). Para a mensuração da PMVT e PMS, foram amostrados dois quadrados de $2 \times 2$ metros (réplicas) em cada piquete, ceifados à altura de $20 \mathrm{~cm}$ do solo. Para a mensuração da altura, foram medidos cinco pontos (réplicas) dentro de cada quadrado de $2 \times 2$ metros, totalizando 10 medições, as quais foram agrupadas em um único valor médio para cada piquete por curva de nível. Para a determinação das diferentes partes da plantas, foram utilizadas 30 plantas íntegras por piquete. Foram considerados como componentes das folhas o limbo e a bainha foliar; e, como componentes da matéria morta, as partes secas da planta. 
Cada amostra foi pré-seca a $55^{\circ} \mathrm{C}$ e, posteriormente, submetida à moagem em moinho estacionário com peneira de crivo de $1 \mathrm{~mm}$. Na fase laboratorial, foram determinados os teores de matéria seca (MS), proteína bruta (PB), extrato etéreo (EE) (Official..., 1995), fibra em detergente neutro (FDN), fibra em detergente ácido (FDA), hemiceluloses (HCEL), nitrogênio insolúvel em detergente ácido (NIDA), nitrogênio insolúvel em detergente neutro (NIDN), celulose (CEL) e ligninas (LIG) (Goering e Van Soest, 1970; Van Soest, 1991) na planta inteira. Os valores de MS também foram determinados nas folhas, hastes e na matéria morta para o cálculo do percentual de cada fração na planta inteira.

Para o experimento in vitro de produção de gases, o material foi amostrado em cada canteiro, seco em estufa de ventilação forçada a $55^{\circ} \mathrm{C}$ por 48 horas. Posteriormente, foi moído em moinho com peneira de $1 \mathrm{~mm}$ de crivo. A metodologia utilizada foi a descrita por Mauricio et al. (1999). $\mathrm{O}$ meio de cultura adicionado aos frascos de incubação foi preparado segundo Theodorou et al. (1994). Utilizou-se inóculo ruminal obtido de um bovino fistulado, alimentado com capimelefante (Pennisetum purpureum) picado, oferecido ad libitum, e, aproximadamente, $1,5 \mathrm{~kg}$ de ração concentrada com $20 \%$ de PB. A pressão de gases foi mensurada nos tempos de 2, 4, 6, 8, $10,12,15,18,21,24,30,36,48,60,72$ e 96 horas de incubação. A relação pressão e volume foi determinada pela equação matemática para este laboratorio, proposta por Mauricio et al. (2003).

Para a descrição da cinética de fermentação, determinaram-se os parâmetros do modelo proposto por France et al. (1993); $P G=A *(1-$ $\left.\exp ^{(-b(t-L A G)-c(\sqrt{ } t-\sqrt{L A G}))}\right)$ e $\mu=b+c /(2 \sqrt{t})$, em que: $A=$ potencial máximo de produção de gases; $L A G=0$ tempo de colonização e hidratação das partículas do substrato; $\mu=$ a taxa fracional de produção de gases; $b$ e $c=$ as taxas fracionais constantes (horas $^{-1}$ e horas $^{-0,5}$ respectivamente) $t=0$ tempo de incubação em horas. Esses parâmetros foram determinados utilizando-se o PROC NLIN do software SAS 6.12/1993. Com base nesses parâmetros e nos valores de DegMS, para cada tratamento, foi calculada a degradabilidade efetiva da MS (DIEMS), considerando as taxas de passagem (kp) de $0,02 / \mathrm{h} ; 0,03 / \mathrm{h}$ e $0,04 / \mathrm{h}$, correspondentes, respectivamente, aos tempos de permanência no rúmen de 50,33 e 25 horas, sendo DIEMS $=S_{0} * \exp ^{-k * L A G}(1-k I) /\left(S_{0}+U_{0}\right)$, em que: $\mathrm{S}_{0}$ é a fração inicialmente fermentavel, $\mathrm{U}_{0}$ é a fração não fermentável, e I é um parâmetro matemático.

O delineamento experimental utilizado para a avaliação estatística das variáveis referentes à produtividade, altura, características agronômicas e composição bromatologica foi em blocos ao acaso, tendo como fontes de variação as curvas em nível (blocos) e idades ao corte (tratamentos). Para a comparação de médias entre tratamentos, foi usado o teste SNK $(\mathrm{P}<0,05)$, utilizando o PROC ANOVA do SAS 6.12/1993. O estudo de regressão e os coeficientes de correlação foram obtidos com auxilio do software PROC CORR e PROC REG do software SAS 6.12/1993. Para a análise dos dados, empregou-se o seguinte modelo estatístico: $Y_{\mathrm{ijk}}=\mu+\mathrm{E}_{\mathrm{i}}+\mathrm{G}_{\mathrm{j}}+\mathrm{e}_{\mathrm{ijk}}$, em que: $\mathrm{Y}_{\mathrm{ijk}}=$ observação "k" na curva em nível "i" submetido à idade de corte "j"; $\mu=$ média geral; $\mathrm{E}_{\mathrm{i}}=$ efeito da curva em nível "i", (i =1, 2, 3, 4); $\mathrm{G}_{\mathrm{j} k}=$ efeito da idade ao corte " $\mathrm{j} ",(\mathrm{j}=42,63,84,107$ e 126); $\mathrm{e}_{\mathrm{ij}}=$ erro experimental.

O delineamento experimental utilizado para a avaliação estatística da produção acumulada de gases foi em blocos ao acaso com parcelas subdivididas, tendo como fontes de variação curvas em nível (blocos), idades de corte (parcelas) e tempos de incubação (subparcelas). Para a comparação de médias entre os tratamentos, foi usado o teste SNK $(\mathrm{P}<0,05)$, utilizando o PROC GLM do software SAS $6.12 / 1993$. Para a análise dos dados, empregouse o seguinte modelo estatístico: $\mathrm{Y}_{\mathrm{ijkz}}=\mu+\mathrm{T}_{\mathrm{z}}+$ $D_{i}+G_{j}+D * G_{i j}+e_{i j k}$, em que: $Y_{i j k}=$ observação " $k$ " na curva de nível " $z$ " da idade ao corte "i" submetido ao tempo de incubação " $\mathrm{j}$; $\mu=$ média geral; $\mathrm{T}_{\mathrm{z}}=$ efeito da curva em nível " $\mathrm{z}$ ", $(\mathrm{j}=1,2$, $3,4) ; D_{i}=$ efeito do tempo de incubação "j", $(j=$ $6,12,24,48$ e 96) $\mathrm{G}_{\mathrm{j}}=$ efeito da idade ao corte "i", (j = 42, 63, 84, 107 e 126); $D * G_{i j}=$ efeito da interação do tempo de incubação "i" com a idade ao corte "j"; $e_{i j}=$ erro experimental.

\section{RESULTADOS E DISCUSSÃO}

$\mathrm{Na}$ Tab. 1, são apresentados os resultados encontrados para altura do relvado (ALT), produtividade de massa de forragem verde (PMFV), produtividade de matéria seca (PMS), 
percentuais de folhas na matéria seca (FMS), percentual de hastes na matéria seca $(\mathrm{MSH})$ e percentual de materia morta na matéria seca morta (MMMS) do capim-tanzânia cortado aos 42, 63, 84, 107 e 126 dias. Foi observado aumento $(\mathrm{P}<0,05)$ na ALT com o aumento da idade ao corte de 42 dias até 84 dias no capimtanzânia. Entre as idades de 84 a 126 dias não se observou diferença para ALT $(\mathrm{P}>0,05)$. O corte do capim-tanzânia à idade de 126 dias foi o que apresentou a maior PMFV $(\mathrm{P}<0,05)$ e não houve diferença na PMFV entre as demais idades $(\mathrm{P}>0,05)$. A maior PMS do capim-tanzânia foi observada no corte aos 126 dias $(\mathrm{P}<0,05)$, seguida pelo corte aos 107 dias, e o menor valor observado ocorreu na forragem cortada aos 42 dias $(\mathrm{P}<0,05)$. Nas idades de corte de 63 e 84 dias, o capim-tanzânia apresentou valores intermediários para PMS.

Tabela 1. Valores médios de altura das plantas (ALT, cm), produção de massa de forragem total (PMFV, $\mathrm{kg} / \mathrm{ha}$ ), produção de matéria seca (PMS kg/ha), percentual de folhas na matéria seca (FMS,\%), percentual de hastes na matéria seca (HMS,\%) e percentual de matéria morta na matéria seca (MMMS,\%) do capimtanzânia cortado aos 42, 63, 84, 107 e 126 dias

\begin{tabular}{lllllll}
\hline Idade ao corte & ALT & PMFV & PMS & FMS & HMS & MMMS \\
\hline 42 & $43,2 \mathrm{C}$ & $8406 \mathrm{~B}$ & $1874 \mathrm{D}$ & $82,0 \mathrm{~A}$ & $0,0 \mathrm{C}$ & $18,0 \mathrm{~A}$ \\
63 & $73,7 \mathrm{~B}$ & $14219 \mathrm{~B}$ & $2938 \mathrm{CD}$ & $89,6 \mathrm{~A}$ & $5,6 \mathrm{BC}$ & $4,8 \mathrm{~B}$ \\
84 & $120,9 \mathrm{~A}$ & $23031 \mathrm{~B}$ & $4910 \mathrm{BC}$ & $83,7 \mathrm{~A}$ & $9,8 \mathrm{~B}$ & $6,5 \mathrm{~B}$ \\
107 & $115,9 \mathrm{~A}$ & $21094 \mathrm{~B}$ & $6183 \mathrm{~B}$ & $80,8 \mathrm{~A}$ & $11,9 \mathrm{~B}$ & $7,3 \mathrm{~B}$ \\
126 & $130,0 \mathrm{~A}$ & $37844 \mathrm{~A}$ & $9743 \mathrm{~A}$ & $65,9 \mathrm{~B}$ & $25,0 \mathrm{~A}$ & $9,1 \mathrm{~B}$ \\
$\mathrm{CV}$ & 18,23 & 35,42 & 30,40 & 6,68 & 41,05 & 41,10 \\
\hline
\end{tabular}

Letras diferentes na coluna representam diferença significativa entre as idades de corte $(\mathrm{P}<0,05$, teste $\mathrm{SNK})$.

Observou-se relação linear para PMFV em função da idade de corte descrita pela equação: PMFV $(\mathrm{kg} / \mathrm{ha})=307,1 *$ idade $($ dias $)-5000,1\left(\mathrm{R}^{2}=\right.$ $0,61 ; \mathrm{P}<0,001)$. Pode-se atribuir um acréscimo de $307,10 \mathrm{~kg} / \mathrm{ha}$ para cada dia de crescimento para o período avaliado. Para PMS e ALT, obtiveram-se as seguintes equações: PMS $(\mathrm{kg} / \mathrm{ha})=89,1 *$ idade $($ dias $)-2390,9\left(\mathrm{R}^{2}=0,77\right.$; $\mathrm{P}<0,001)$ e $\operatorname{ALT}(\mathrm{cm})=1,0 *$ idade $($ dias $)+10,9$ $\left(\mathrm{R}^{2}=0,67 ; \mathrm{P}<0,001\right)$.

Azevedo et al. (1992) relataram medidas de altura do relvado do capim-tanzânia nas idades de $28,56,84$ e 112 dias de $40,5 \mathrm{~cm}, 63,0 \mathrm{~cm}$, $91,0 \mathrm{~cm}$ e $99,7 \mathrm{~cm}$, respectivamente. Gerdes et al. (2000) citaram valores de altura do relvado de capim-tanzânia cortado aos 35 dias de $77,8 \mathrm{~cm}$

Segundo Santos et al. (1999), o valor de produção de massa de forragem para o capimtanzânia em pastejo, no intervalo de 48 dias, foi de $6757 \mathrm{~kg} / \mathrm{ha}$. Ezequiel e Favoretto (2000) observaram o valor de PMS para o capimcolonião, cortado aos 42 dias, de $2126,3 \mathrm{~kg} / \mathrm{ha}$ e Gerdes et al. (2000), para o capim-tanzânia, cortado aos 35 dias, o de $2880 \mathrm{~kg} / \mathrm{ha}$.

Santos et al. (1999) descreveram taxas de acúmulo de MS para o capim-tanzânia de 79,8 a $150,1 \mathrm{~kg} / \mathrm{ha} /$ dia durante o período das águas.
Gomide e Zago (1980), ao avaliarem a taxa de crescimento do capim-colonião cortado de dois a 63 dias, a intervalos de sete dias, verificaram taxa de acúmulo de MS de 75,8kg MS/ha/dia, e Botrel et al.(1987), taxa de crescimento do capim Panicum maximum de $2390 \mathrm{~kg} \mathrm{MS} / \mathrm{ha} / 30$ dias (79,7kg MS/ha/dia) para o cv Makueni, e de 2060kg MS/ha/30 dias (69,7kg MS/ha/dia) para o cv Green Panic, no período das águas.

Fatores como solo, adubação, luminosidade, temperatura, pluviosidade e duração dos dias afetam a taxa de crescimento da planta e, consequentemente, seu desenvolvimento e a sua produtividade (Harrison et al., 1994; Van Soest, 1994). Por isso, sugere-se que os valores de produtividade de uma forrageira sejam avaliados de forma conjunta com as características agronômicas, pois as folhas são mais ricas em nutrientes que as hastes (Van Soest, 1994), sendo fundamental essa avaliação para a determinação do melhor momento de corte do capim-tanzânia.

O percentual de FMS (Tab. 1) manteve-se, respectivamente, entre $80,8 \%$ a $89,6 \%$ até a idade de 107 dias, sem apresentar diferença entre os tratamentos $(\mathrm{P}>0,05)$. A FMS do capimtanzânia, cortado aos 126 dias, foi menor que a do corte nas demais idades $(\mathrm{P}<0,05)$. Para a FMS encontrou-se a equação: FMS $(\%)=53,949+$ 
0,969* idade (dias) - 0,006*idade ${ }^{2}, \quad\left(\mathrm{R}^{2}=0,64\right.$, $\mathrm{P}<0,001)$. Jank et al. (1997) citaram valor mais baixo que o observado neste experimento para a FMS do capim-tanzânia cortado aos 56 dias $(79,8 \%)$, e Gerdes et al. (2000) relataram valores de $81,9 \%$ para FMS para o capim-tanzânia cortado aos 35 dias, próximo ao observado neste experimento para a forragem cortada aos 42 dias.

São observados maiores teores de PB na lâmina foliar que nas hastes no capim-tanzânia, enquanto, nas hastes, observa-se maior teor de FDN que nas folhas (Gerdes et al., 2002). Isso se deve à presença de tecidos vegetais relacionados ao processo de fotossíntese nas folhas. Tecidos vegetais relacionados ao processo de assimilação do carbono são ricos em cloroplastos, estrutura responsável pela fotossíntese, com grande acúmulo de proteína na forma de enzimas, e apresentam células com parede celular delgada e não lignificada (Paciullo, 2002). Dessa forma, é desejável a busca pela idade ao corte de uma forrageira, em que haja maior teor de folhas.

Para a HMS (Tab. 1), observou-se acréscimo gradativo em função da idade ao corte do capimtanzânia $(\mathrm{P}<0,05)$. Este pode ser descrito pela equação: HMS $(\%)=-11,81+0,264 *$ idade (dias) $\left(\mathrm{R}^{2}=0,74 ; \mathrm{P}<0,001\right)$. $\mathrm{O}$ aumento nos valores de HMS, com o avançar da idade da forrageira, interfere diretamente no valor nutritivo da forrageira. Wilson e Hatfield (1997) associaram o decréscimo da digestibilidade em forrageiras tropicais ao aumento da participação de hastes na composição agronômica da planta. Segundo esses autores, esse componente da planta apresenta em sua composição tecidos vegetais de menor taxa de degradação ruminal (esclerênquima e xilema). Estas consistem de tecidos vegetais de sustentação e vascular, com células densamente agrupadas e com paredes espessadas e lignificadas (Van Soest, 1994; Paciullo, 2002; Paciullo et al., 2002).

Para o MMMS (Tab. 1), observou-se o maior valor para o capim-tanzânia cortado aos 42 dias $(\mathrm{P}<0,05)$, sendo os demais tratamentos iguais entre si $(P>0,05)$. Para essa variável não foi determinada a equação de regressão por apresentar baixo coeficiente de determinação e significância. Costa et al. (1992) observaram que ocorre aumento na proporção de material seco na planta dos capins tobiatã e colonião, com o avançar da idade ao corte de 28 aos 42 dias, atribuindo a este fato o aumento do processo de senescência com o aumento da idade ao corte das forrageiras.

Os teores de MS, matéria mineral (MM), matéria orgânica (MO), EE e PB do capim-tanzânia, cortado nas diferentes idades, são apresentados na Tab. 2. Observou-se o maior teor de MS no corte à idade de 107 dias $(\mathrm{P}<0,05)$, e entre as demais idades ao corte não houve diferença significativa $(\mathrm{P}>0,05)$. Os valores de $\mathrm{MS}$ são expressos pela equação: $\mathrm{MS}(\%)=18,57+0,06^{*}$ idade (dias) $\left(\mathrm{R}^{2}=0,33 ; \mathrm{P}<0,01\right)$. Pelo baixo coeficiente de determinação apresentado pela equação, pode-se inferir que a idade ao corte explicou, parcialmente, a variação no teor de MS do capim-tanzânia.

Teor de MS de 19,5\% foi observado por Gerdes et al. (2000) para o corte aos 35 dias, e Gerdes et al. (2002) observaram teor de MS de 20,9\% para o corte aos 145 dias.

Tabela 2. Valores médios dos teores de matéria seca (MS,\%), matéria mineral (MM,\%), matéria orgânica (MO,\%), extrato etéreo (EE,\%) e proteína bruta (PB,\%) no capim-tanzânia, cortado aos 42, 63, 84, 107 e 126 dias

\begin{tabular}{llllll}
\hline Idade ao corte & MS & MM & MO & EE & PB \\
\hline 42 & $22,70 \mathrm{~B}$ & 10,86 & 89,14 & 1,41 & $9,77 \mathrm{~A}$ \\
63 & $21,65 \mathrm{~B}$ & 11,44 & 88,56 & 1,39 & $7,66 \mathrm{~B}$ \\
84 & $21,80 \mathrm{~B}$ & 11,23 & 88,77 & 0,74 & $6,22 \mathrm{~B}$ \\
107 & $29,64 \mathrm{~A}$ & 10,26 & 89,74 & 0,44 & $3,87 \mathrm{C}$ \\
126 & $25,77 \mathrm{~B}$ & 9,97 & 90,03 & 0,41 & $3,78 \mathrm{C}$ \\
CV & 9,49 & 8,46 & 1,02 & 18,12 & 78,57 \\
\hline
\end{tabular}

Letras diferentes na coluna representam diferença significativa entre idades de corte. $(\mathrm{P}<0,05$; teste $\mathrm{SNK}) . \mathrm{CV}=$ coeficiente de variação. Valores em percentual da matéria seca. 
Acredita-se que possa haver alguma relação entre os teores de MS e as condições climáticas nos dias que antecederam ao corte, pois o experimento foi realizado durante a estação do ano com grande ocorrência de chuvas, o que pode ter levado ao acúmulo de orvalho na forrageira em alguns cortes. Este fato é importante quando o objetivo é a ensilagem da forrageira, pois a ocorrência de chuvas nos dias que antecedem ao corte influencia o teor de MS da forragem e pode aumentar as perdas durante a ensilagem (McDonald et al., 1991).

Para MO, MM e EE (Tab. 2), não houve diferença $(\mathrm{P}>0,05)$ entre os teores encontrados. Devasena et al. (1994) descreveram decréscimo nos teores MM e EE no capim-colonião com o avançar da idade ao corte de 15 a 90 dias, em intervalos de 15 dias. Nas plantas forrageiras, cerca de $50 \%$ do conteúdo da fração EE corresponde a óleos essenciais ou apenas a substâncias solúveis em solvente apolar, com valor nutricional irrisório (Van Soest, 1994).

Observou-se o decréscimo dos teores de PB do capim-tanzânia com o aumento da idade ao corte $(\mathrm{P}<0,05)$, apresentando comportamento linear descrito pela equação: $\mathrm{PB}(\%)=12,57-$ $0,074 *$ idade (dias) $\left(\mathrm{R}^{2}=0,82 ; \mathrm{P}<0,001\right)$. Teor de PB de $11,7 \%$ foi observado por Jank et al. (1997) para o capim-tanzânia, cortado aos 56 dias. Gerdes et al. (2000) encontraram, para o capim cortado aos 35 dias, teor de $10,8 \%$ de PB e Gerdes et al. (2002), teor de $11,4 \%$ aos 145 dias. Devasena et al. (1994) e Benedetti et al. (2001) observaram decréscimo nos teores de PB de cultivares de Panicum maximum com o avançar da idade ao corte.

Neste experimento, foram obtidos valores mais baixos que $6 \%$ de $\mathrm{PB}$, a partir do corte do capim- tanzânia aos 84 dias. Segundo Van Soest (1994), valores de PB menores que a $6 \%$ afetam a fermentação ruminal, pela diminuição da atividade microbiana causada pela deficiência de nitrogênio, e influenciam o consumo voluntário e o coeficiente de digestibilidade da forrageira. Dessa forma, os resultados obtidos sugerem a utilização do capim-tanzânia em idades inferiores a 84 dias de crescimento vegetativo, quando fornecido como forragem fresca.

O teor encontrado para PB nas diferentes idades reflete a composição agronômica dessa forrageira. Observou-se correlação negativa entre PB e HMS, -0,69, e correlação positiva entre PB e FMS, 0,43, corroborando as afirmações feitas anteriormente quanto à composição de tecidos da folha e haste da planta do capim-tanzânia. Dessa forma, o aumento na idade ao corte pode resultar em menor teor de PB pela diminuição do percentual de folhas e conteúdo celular da forrageira (Buxton, 1996).

Na Tab. 3, são apresentados os teores de FDN, FDA, HCEL, CEL e LIG do capim-tanzânia, cortado em diferentes idades. Observou-se aumento dos teores de FDN com o aumento da idade ao corte $(\mathrm{P}<0,05)$, sendo os maiores observados na forrageira cortada aos 126 dias $(\mathrm{P}>0,05)$ e o menor nos cortes aos 42 e 63 dias $(\mathrm{P}<0,05)$, e valores intermediários nos cortes aos 84 e aos 107 dias. Para a FDA, não houve diferença entre os cortes aos 42, 63, 84 e 107 dias $(\mathrm{P}>0,05)$, e somente a forrageira cortada aos 126 dias apresentou maior teor de FDA que os demais tratamentos $(\mathrm{P}<0,05)$. A FDN e a FDA apresentaram comportamento linear em função da idade ao corte, sendo representadas pelas equações: $\mathrm{FDN}(\%)=67,25+0,07 *$ idade (dias) $\quad\left(\mathrm{R}^{2}=0,52 ; \quad \mathrm{P}<0,001\right)$ e $\operatorname{FDA}(\%)=$ $32,18+0,08 *$ idade (dias) $\left(\mathrm{R}^{2}=0,70, \mathrm{P}<0,001\right)$.

Tabela 3. Valores médios dos teores de fibra em detergente neutro (FDN,\%), fibra em detergente ácido (FDA,\%), hemiceluloses (HCEL,\%), celulose (CEL,\%) e lignina em detergente ácido (LIG,\%) no capimtanzânia, cortado aos 42, 63, 84, 107 e 126 dias

\begin{tabular}{llllll}
\hline Idade ao corte & FDN & FDA & HCEL & CEL & LIG \\
\hline 42 & $69,98 \mathrm{~B}$ & $36,10 \mathrm{~B}$ & 33,85 & $29,79 \mathrm{~B}$ & $6,22 \mathrm{AB}$ \\
63 & $71,75 \mathrm{~B}$ & $37,00 \mathrm{~B}$ & 34,66 & $31,78 \mathrm{AB}$ & $4,84 \mathrm{~B}$ \\
84 & $73,95 \mathrm{AB}$ & $39,73 \mathrm{~B}$ & 34,02 & $33,64 \mathrm{AB}$ & $5,82 \mathrm{AB}$ \\
107 & $73,32 \mathrm{AB}$ & $39,95 \mathrm{~B}$ & 33,84 & $33,15 \mathrm{AB}$ & $6,20 \mathrm{AB}$ \\
126 & $76,64 \mathrm{~A}$ & $43,60 \mathrm{~A}$ & 32,81 & $34,15 \mathrm{~A}$ & $8,93 \mathrm{~A}$ \\
$\mathrm{CV}$ & 3,071 & 4,071 & 2,81 & 5,73 & 27,16 \\
\hline
\end{tabular}

Letras diferentes na coluna representam diferença significativa entre idades de corte $(\mathrm{P}<0,05$; teste $\mathrm{SNK})$. $\mathrm{CV}=$ coeficiente de variação. Valores em percentual da matéria seca. 
Gerdes et al. (2000) relataram teor de FDN do capim-tanzânia cortado aos 35 dias de 78,14\%. Gerdes et al. (2002) citam teor de FDN para o capim-tanzânia, cortado aos 145 dias, de 73,79\%. Devasena et al. (1994) e Benedetti et al. (2001) observaram aumento linear nos teores de FDN e FDA em cultivares de Panicum maximum com o avançar da idade ao corte.

O FDN é tido como o principal constituinte químico da forragem relacionado ao consumo voluntário (Jung e Allen, 1995) e o FDA está relacionado a alterações do coeficiente de digestibilidade da forrageira (Van Soest, 1994). Com isso espera-se que, com o aumento da idade ao corte do capim-tanzânia, haja diminuição do consumo voluntário e da digestibilidade, pois com a maturidade ocorre aumento da deposição de parede celular nos tecidos das hastes (Jung e Allen, 1995). Esse fato pode ser demonstrado pelo coeficiente de correlação positivo obtido para FDN e HMS $(r=0,79)$. No entanto, quando o objetivo é a ensilagem, o teor de FDN pode contribuir como substrato para a fermentação pela hidrólise das hemiceluloses, liberando açúcares para as bactérias ácido-láticas (McDonald et al., 1991; Henderson, 1993).

Para a HCEL (Tab. 3) não foi observada diferença entre os tratamentos $(\mathrm{P}>0,05)$, ficando os teores nas diferentes idades ao corte entre $32,8 \%$ e $34,7 \%$. Benedetti et al. (2001) estudaram o capim-tanzânia cortado aos 30, 45, 60 e 75 dias e também não observaram diferença significativa para os teores de HCEL entre as idades ao corte. As HCEL são polissacarídeos complexos, que podem ser divididos quanto ao açúcar constituinte em pentosanas e hexosanas. As pentosanas são compostas principalmente por xilanas e arabinoxilanas, enquanto as hexosanas o são por mananas, glucanas, glucomananas e galactanas (Giger-Reverdin, 1995). Segundo Chesson e Forsberg (1997), com a maturidade da forrageira, observam-se alterações mais significativas em relação à composição dos açúcares da HCEL que em sua concentração na planta.

Para a CEL, o maior teor ocorreu no corte aos 126 dias, diferindo do corte aos 42 dias $(\mathrm{P}<0,05)$. Os demais tratamentos apresentaram valores intermediários e não diferiram entre si $(\mathrm{P}>0,05)$. O comportamento dos teores de CEL em função da idade ao corte do capim-tanzânia é descrito pela equação: $\operatorname{CEL}(\%)=0,05 *$ idade $($ dias $)+28,50$ $\left(\mathrm{R}^{2}=0,40 ; \mathrm{P}<0,01\right)$.

Devasena et al. (1994) verificaram aumento nos teores de CEL de 24,6 a $34,5 \%$ no capimcolonião cortado dos 15 aos 90 dias de idade, a intervalos de 15 dias, enquanto Benedetti et al. (2001) observaram para o capim cortado aos 30, 45, 60 e 75 dias, na estação chuvosa, teores de CEL de $30,4 \%, 32,8 \%, 33,3 \%$ e $34,5 \%$, respectivamente. Nos dois estudos, os valores ficaram próximos aos observados neste experimento para o capim-tanzânia.

A celulose consiste de polímeros de glicose com ligações $\beta$ 1-4, com regiões cristalinas e amorfas em sua microfibrila (Giger-Reverdin, 1995). Com o aumento da idade de corte, há incorporação de polissacarídeos entre as microfibrilas de celulose na parede celular vegetal. Arabinoxilanas e xiloses são depositadas entre as moléculas, na tentativa de organizar as microfibrilas, aumentando a cristalinidade da cadeia de polissacarídeos com o aumento da idade da forrageira (Moore e Hatfield, 1994; Chesson e Forsberg, 1997).

O menor teor de LIG no capim-tanzânia foi observado no corte aos 63 dias $(\mathrm{P}<0,05)$, maior que o teor verificado no corte aos 126 dias $(\mathrm{P}<0,05)$. Os demais tratamentos apresentaram valores intermediários e não diferentes entre si ( $\mathrm{P}>0,05)$. $\mathrm{O}$ alto valor apresentado pelo corte aos 42 dias embasa a constatação anterior de possível ocorrência de contaminação com resíduos de forragem seca presentes no solo. $\mathrm{O}$ comportamento dos teores de LIG foi descrito pela equação: $\operatorname{LIG}(\%)=0,001{ }^{*}$ idade $\quad(\text { dias })^{2}$ $0,18 *$ idade (dias) $+11,44 \quad\left(\mathrm{R}^{2}=0,43 ; \quad \mathrm{P}<0,01\right)$. Certo cuidado deve-se ter ao analisar os valores de LIG obtidos por metodologia sequencial, pois problemas relativos às etapas anteriores de determinação podem ter ocasionado este resultado, que é de difícil interpretação.

Devasena et al. (1994) observaram aumento nos teores de LIG de $5,4 \%$ a $11,0 \%$ no capimcolonião, cortado dos 15 aos 90 dias de idade, a intervalos de 15 dias. Os teores de LIG apresentaram alta correlação com os percentuais de HMS, 0,68, e correlação negativa com FMS, 0,68 , corroborando a afirmação de que a haste é composta por tecidos vegetais altamente lignificados e as folhas por tecidos menos 
lignificados. As ligninas são constituídas de macromoléculas de estrutura complexa e alto peso molecular (Giger-Reverdin, 1995). Com o desenvolvimento da forrageira, esses compostos substituem os espaços na matriz da parede celular ocupados por água, aumentando a rigidez da parede celular (Giger-Reverdin, 1995). As ligninas afetam a digestibilidade da matéria seca por se ligarem aos componentes da parede celular, sendo a ocorrência dessa interação aumentada com a maturidade da forrageira, seja pelo aumento da concentração de LIG e/ou pela modificação na composição dos compostos fenólicos (Jung, 1989; Jung e Allen, 1995; Wilson e Hatfield, 1997).

Na Tab. 4, são apresentados os teores de nitrogênio insolúvel em detergente neutro (NIDN), nitrogênio insolúvel em detergente neutro em percentual do nitrogênio total (NIDN/N), nitrogênio insolúvel em detergente ácido (NIDA) e nitrogênio insolúvel em detergente ácido em percentual do nitrogênio total (NIDA/N) do capim-tanzânia cortado aos 42, 63, 84, 107 e 126 dias. Observou-se decréscimo nos valores de NIDN com o avançar da idade ao corte da forrageira até a idade de 107 dias $(\mathrm{P}<0,05)$. No capim-tanzânia cortado aos 107 dias e 126 dias não foi observada diferença significativa para os teores de NIDN $(\mathrm{P}>0,05)$. A ausência de diferença observada para os teores de NIDN/N pode ser atribuída ao decréscimo nos teores de $\mathrm{PB}$ que, com isso, mantiveram semelhantes esses valores. Os teores de NIDN apresentaram comportamento linear em função da idade ao corte do capim-tanzânia sendo descrito pela equação: $\operatorname{NIDN}(\%)=0,95$ $0,01 *$ idade (dias), $\mathrm{R}^{2}=0,72, \mathrm{P}<0,001$.
Com relação aos teores de NIDN/N e NIDA, não foram observadas diferenças significativas entre os tratamentos $(\mathrm{P}>0,05)$. Os teores de NIDA/N não foram diferentes no capim-tanzânia cortado aos 42 dias e 63 dias $(\mathrm{P}>0,05)$, sendo estes menores que no corte à idade de 126 dias $(\mathrm{P}<0,05)$. O capim-tanzânia cortado aos 84 dias e o cortado aos 107 dias apresentaram valores intermediários aos demais para NIDA/N $(\mathrm{P}>0,05)$. $\mathrm{O}$ teor de NIDA/N descreveu comportamento linear expresso pela equação: $\mathrm{NIDA} / \mathrm{N}(\%)=0,94-0,07 *$ idade $\quad($ dias $), \mathrm{R}^{2}=0,44$, $\mathrm{P}<0,001$.

Valadares Filho et al. (2006) citam como teores de NIDN/N e NIDA/N, respectivamente, 41,1\% e $16,6 \%$ para o capim-tanzânia. A fração NIDN consiste dos compostos nitrogenados associados à parede celular vegetal, apresentando, dessa maneira, degradabilidade lenta no rúmen. A fração NIDA consiste dos compostos nitrogenados associados à lignina, taninos e a produtos da reação de Maillard, sendo estes altamente resistentes à ação das enzimas microbianas e intestinais (Sniffen et al., 1992). Pode-se inferir que, com o aumento da idade ao corte do capim-tanzânia, ocorre maior associação entre compostos nitrogenados e a parede celular, e, com isso, há diminuição da disponibilidade desses compostos devido à formação de complexos que são resistentes à ação das enzimas microbianas e intestinais. Isso vai ao encontro da correlação encontrada entre HMS e NIDA/N, de 0,60, e, com estes resultados, tornam-se mais limitantes os teores de PB.

Tabela 4. Valores médios dos teores de nitrogênio insolúvel em detergente neutro (NIDN,\%), nitrogênio insolúvel em detergente neutro em percentual do nitrogênio total (NIDN/N,\%), nitrogênio insolúvel em detergente ácido (NIDA,\%) e nitrogênio insolúvel em detergente ácido em percentual do nitrogênio total (NIDA/N,\%) no capim-tanzânia cortado aos 42, 63, 84, 107 e 126 dias

\begin{tabular}{lllll}
\hline Idade ao corte & NIDN & NIDN/N & NIDA & NIDA/N \\
\hline 42 & $0,77 \mathrm{~A}$ & 48,64 & 0,08 & $5,49 \mathrm{~B}$ \\
63 & $0,53 \mathrm{~B}$ & 44,59 & 0,04 & $3,57 \mathrm{~B}$ \\
84 & $0,46 \mathrm{BC}$ & 46,85 & 0,06 & $6,80 \mathrm{AB}$ \\
107 & $0,26 \mathrm{C}$ & 42,14 & 0,05 & $8,30 \mathrm{AB}$ \\
126 & $0,29 \mathrm{C}$ & 47,94 & 0,06 & $10,72 \mathrm{~A}$ \\
$\mathrm{CV}$ & 23,96 & 14,93 & 38,12 & 35,2 \\
\hline
\end{tabular}

Letras diferentes na coluna representam diferença significativa entre idades de corte $(\mathrm{P}<0,05 ; \mathrm{SNK})$. CV = coeficiente de variação. Valores em percentual da matéria seca. 
Na Fig. 1, foram descritas as curvas da taxa de produção de gases em função dos tempos de incubação, em que se podem destacar três grupos. O primeiro grupo, formado pelo capimtanzânia cortado aos 42 dias, ocorreu a maior taxa de produção de gases em torno de 24 horas em relação às taxas apresentadas pelos demais tratamentos. Esse fato pode ser atribuído ao maior conteúdo celular na célula vegetal em idades mais jovens, o qual é fermentado mais rapidamente no rúmen (Jung, 1989; Van Soest,
1994). O segundo grupo é formado pelo capimtanzânia cortado aos 63 dias, com aumento nas taxas de produção de gases após as 24 horas, sendo estas mais altas que as da forrageira cortada aos 84, 107 e 126 dias, e superando o corte aos 42 dias a partir das 48 horas de incubação. Com o aumento da idade ao corte, ocorreu a substituição parcial do conteúdo celular por parede celular vegetal (Van Soest, 1994). A parede celular apresentou maior taxa de fermentação em períodos mais tardios.

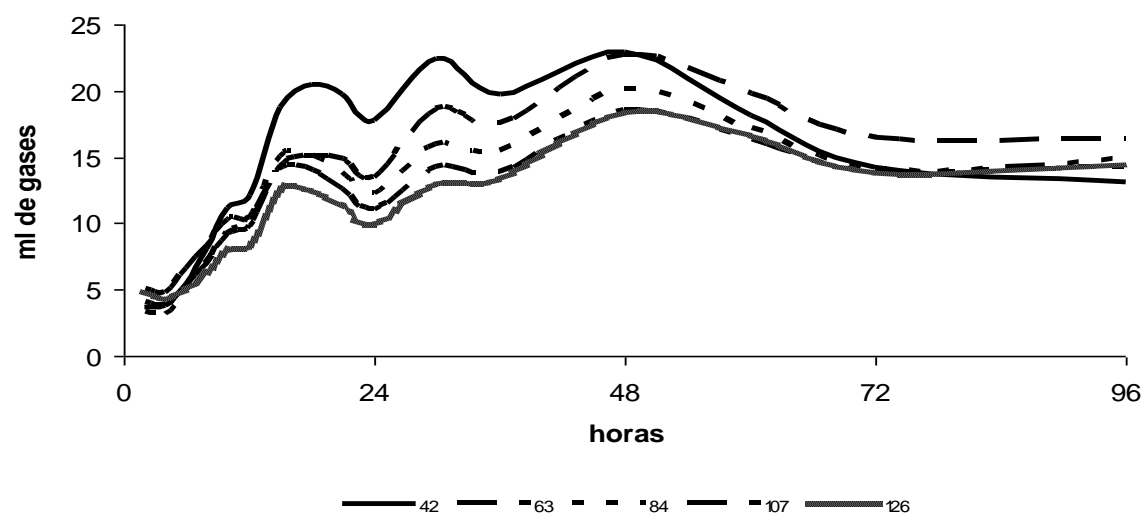

Figura 1. Taxa de produção total de gases $\left(\mathrm{mL} / \mathrm{g}\right.$ de matéria seca/hora $\left.{ }^{-1}\right)$ do capim-tanzânia cortado aos $42,63,84,107$ e 126 dias.

$\mathrm{Na}$ Tab. 5, são apresentados os valores de produção acumulada de gases para o capimtanzânia cortado aos 42, 63, 84, 107 e 126 dias, representado também na Fig. 2. Para todos os tratamentos, a produção acumulada de gases aumentou em função do tempo de incubação $(\mathrm{P}<0,05)$, com a assíntota sendo observada a partir de 96 horas. Em relação aos tratamentos, apenas foram observadas diferenças entre eles a partir de 24 horas de incubação. Para os tempos de 24,48 e 96 horas, o capim cortado aos 42 dias foi o que apresentou a maior produção acumulada de gases $(\mathrm{P}<0,05)$. No tempo de 24 horas de incubação, a produção acumulada de gases do capim cortado aos 63, 84, 107 e 126 dias, de idades não diferiu $(\mathrm{P}>0,05)$ entre si. No tempo de 48 horas, na forrageira cortada aos 63, 84 e 107 dias, ocorreu maior produção acumulada de gases que na cortada aos 126 dias $(\mathrm{P}<0,05)$. No tempo de 96 horas, o capim cortado aos 63 dias resultou em maior produção de gases $(\mathrm{P}<0,05)$ que o cortado aos 84 e 107 dias, os quais foram semelhantes $(\mathrm{P}>0,05)$ entre si.

Tabela 5. Valores médios de produção acumulada de gases $(\mathrm{mL} / \mathrm{g}$ de matéria seca) do capim-tanzânia cortado aos 42, 63, 84, 107 e 126 dias

\begin{tabular}{llllll}
\hline \multirow{2}{*}{ Idade ao corte } & \multicolumn{5}{c}{ Horas } \\
\cline { 2 - 6 } & 6 & 12 & 24 & 48 & 96 \\
\hline 42 & $12,96 \mathrm{Ae}$ & $44,30 \mathrm{Ad}$ & $120,98 \mathrm{Ac}$ & $186,11 \mathrm{Ab}$ & $231,57 \mathrm{Aa}$ \\
63 & $13,12 \mathrm{Ae}$ & $39,13 \mathrm{Ad}$ & $96,84 \mathrm{Bc}$ & $155,53 \mathrm{Bb}$ & $207,99 \mathrm{Ba}$ \\
84 & $11,40 \mathrm{Ae}$ & $38,09 \mathrm{Ad}$ & $94,39 \mathrm{Bc}$ & $145,79 \mathrm{Bb}$ & $191,35 \mathrm{Ca}$ \\
107 & $16,36 \mathrm{Ae}$ & $45,49 \mathrm{Ad}$ & $97,17 \mathrm{Bc}$ & $143,78 \mathrm{Bb}$ & $188,82 \mathrm{Ca}$ \\
126 & $14,16 \mathrm{Ae}$ & $36,70 \mathrm{Ad}$ & $82,90 \mathrm{Bc}$ & $127,67 \mathrm{Cb}$ & $172,55 \mathrm{Da}$ \\
\hline
\end{tabular}

Letras minúsculas diferentes na linha e maiúsculas diferentes na coluna representam diferença significativa entre horas e idades de corte, respectivamente $(\mathrm{P}<0,05$; SNK). Coeficiente de variação erro $\mathrm{A}=4,2 \%$. Coeficiente de variação erro $B=4,3 \%$. 


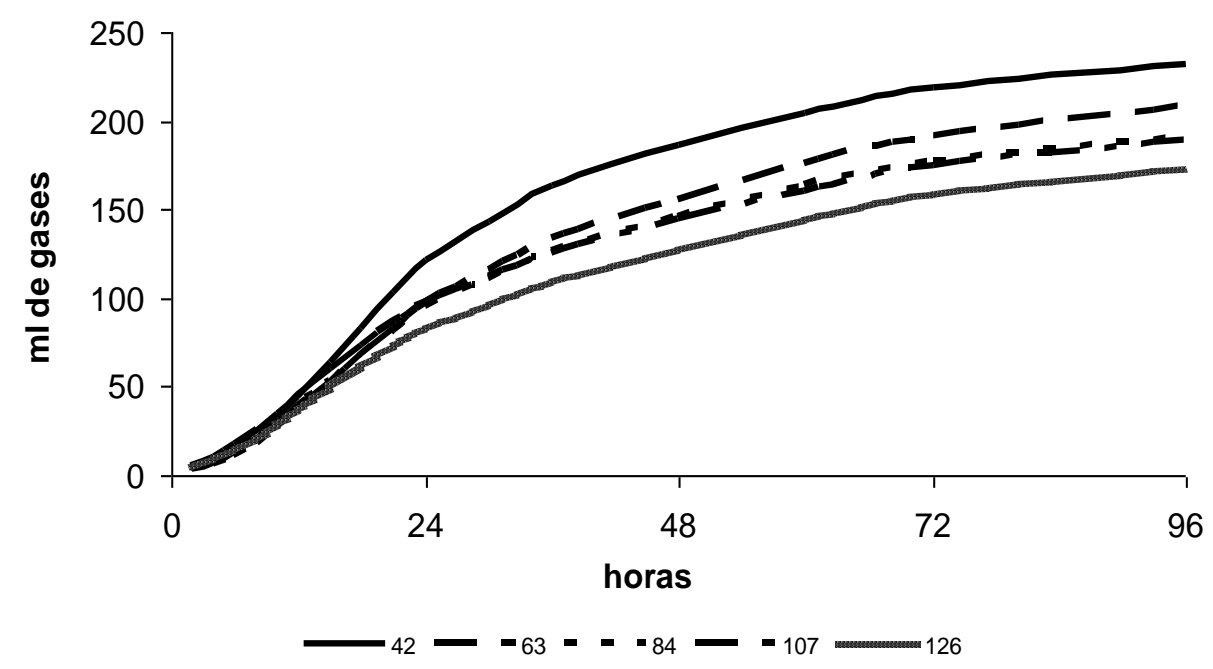

Figura 2. Produção acumulada de gases (mL/g de matéria seca) do capim-tanzânia, cortado aos 42, 63, 84, 107 e 126 dias.

Para o capim-tanzânia cortado aos 63 dias, apesar do menor teor de LIG (Tab. 3), o maior teor de parede celular e, talvez, a maior espessura desta, devido ao maior percentual de hastes (Tab. 1), podem ter sido os limitantes no potencial de fermentação. O capim-tanzânia cortado aos 84 e 107 dias apresentou potencial de fermentação semelhante em todos os tempos de incubação, fato que pode ser atribuído ao reflexo dos teores de LIG e CEL (Jung, 1989; Jung e Allen, 1995), pois estes foram semelhantes entre os dois tratamentos $(\mathrm{P}>0,05)$.

A menor produção acumulada de gases foi observada para o capim-tanzânia cortado aos 126 dias, o que pode ser reflexo dos maiores teores de CEL e LIG (Tab. 3), os quais afetaram tanto a taxa quanto o potencial de fermentação in vitro. As ligninas ligam-se aos componentes da parede celular, tendo a ocorrência dessa interação aumentada com a maturidade da forrageira, seja pelo aumento da concentração de LIG e/ou pela modificação na composição dos compostos fenólicos, que afetam a extensão da degradação da forrageira (Jung, 1989; Jung e Allen, 1995). De forma conjunta, observa-se aumento da hidrofobicidade da cadeia de celulose na parede celular, o que, consequentemente, pode diminuir a taxa de degradação da forrageira (Chesson e Forsberg, 1997).

Os parâmetros do modelo de France et al. (1993) para descrever a produção acumulada de gases e a DIEMS para cada tratamento são apresentados na Tab. 6. O potencial máximo de produção de gases (A) e o tempo de colonização e hidratação das partículas do substrato (LAG) diminuíram com o aumento da idade ao corte. O maior valor da taxa fracional de produção de gases $(\mu)$ foi observado no capim cortado aos 42 dias, seguido de valores mais baixos, nos cortes de 84, 107 e 63 dias. Aos 126 dias, verificou-se o menor valor de $\mu$. Cone et al. (1999) observaram que o aumento da maturidade das plantas resultou em diminuição na $\mu$ e na PG. Esses resultados ocorreram em função da diminuição da fermentabilidade da forrageira com o aumento da idade ao corte. De maneira geral, parece ter ocorrido tal fato no presente experimento para os valores de $A$ e $\mu$. Essa menor fermentabilidade está diretamente relacionada ao aumento dos teores e da disponibilidade da parede celular com o aumento da idade da forrageira (Jung e Allen, 1995). 
Tabela 6. Parâmetros da curva de produção acumulada de gases e degradabilidade efetiva da matéria seca (DIEMS), segundo France (1993), para o capim-tanzânia cortado aos 42, 63, 84, 107 e 126 dias

\begin{tabular}{lllllll}
\hline \multirow{2}{*}{ Idade ao corte } & $\mathrm{A}$ & \multirow{2}{*}{$\mathrm{L}$} & $\mathrm{LAG}$ & \multicolumn{3}{c}{ DIEMS } \\
\cline { 5 - 7 } & & & & 0,02 & 0,03 & 0,04 \\
\hline 42 & 229,50 & 0,04267 & $2: 41$ & 46,52 & 40,04 & 35,60 \\
83 & 214,28 & 0,03259 & $1: 48$ & 39,20 & 33,97 & 30,73 \\
107 & 193,29 & 0,03551 & $1: 41$ & 38,19 & 33,60 & 30,57 \\
126 & 193,61 & 0,03266 & $1: 23$ & 38,01 & 33,68 & 31,01 \\
\hline
\end{tabular}

A: potencial máximo de produção de gases, $\mu$ : taxa fracional de produção de gases, LAG: tempo de colonização e hidratação das particulas do substrato.

De modo geral, os valores de DIEMS diminuíram com o aumento da idade ao corte do capim-tanzânia em todas as taxas de passagem. Dessa forma, pode-se inferir que, com o aumento da idade ao corte, ocorre diminuição da degradabilidade da forrageira, devido ao aumento do percentual de hastes ou diminuição do percentual de folhas, o que resulta em aumento da cristalinidade da celulose e dos teores de lignina na parede celular (Jung, 1989; Jung e Allen, 1995). Tal afirmação é comprovada pelo estudo de correlação entre os resultados obtidos para a composição agronômica, composição bromatológica e volume acumulado de produção in vitro de gases às 24 (G24) e 48 horas (G48), de incubação do capim-tanzânia. Observaram-se altos coeficientes de correlação entre G24 e G48 respectivamente, com HMS (-0,74 e -0,80), FDN (-0,76 e -0,75), FDA $(-0,75$ e $-0,77)$, e PB $(0,70$ e 0,82$)$, demonstrando que a composição agronômica e bromatológica refletiram na técnica in vitro.

\section{CONCLUSÕES}

Recomenda-se o corte do capim-tanzânia entre as idades de 42 a 63 dias de crescimento para a confecção de silagem, tomando por base os resultados encontrados para produtividade, composição agronômica, composição bromatológica e cinética de fermentação ruminal dessa forrageira.

\section{REFERÊNCIAS BIBLIOGRAFICAS}

AZEVEDO, G.P.C.; CAMARÃO, A.P.; GONÇALVES, C.A. Produção forrageira $e$ valor nutritivo dos capins: quicuio-da-amazônia, marandu, tobiatã, andropogon, e tanzânia-1 em quatro idades de corte. Belém: EmbrapaCPATU, 1992. 31p. (Boletim, 126).
BENEDETTI, E.; COLMANETTI, A.L.; DEMETRIO, R.A. Produção e composição bromatólogica do capim Panicum maximum Jacq. cv. Tanzânia irrigado em solo de cerrado. Vet. Not., v.7, p.123-128, 2001.

BOTREL, M.A.; ALVIM, M.J.; MOZZER, O.L. Avaliação agronômica de gramíneas forrageiras sob pastejo. Pesqu. Agropec. Bras., v.22, p.10191025, 1987.

BUXTON, D.R. Quality related-characteristics of forages as influenced by plant environment and agronomic factors. Anim. Feed Sci. Technol., v.59, p.37-49, 1996.

CHESSON, A.; FORSBERG, C.W. Polysaccharide degradation by rumen microorganisms. In: HOBSON, P.N. e STEWART, C.S. (Eds). The rumen microbial ecosystem. Londres: Brackie Academic \& Professional, 1997. cap.8, p.329-381.

CONE, J.W.; VAN GELDER, A.H.; SOLIMAN, I.A. et al. Different techniques to study rumen fermentation characteristics of maturing grass and grass silage. J. Dairy Sci., v.62, p.957-966, 1999.

COSTA, C.; FAVORETTO, V.; MALHEIROS, E.B. Estudo da variação na estrutura da vegetação de duas cultivares de Panicum maximum Jacq. (colonião e tobiatã) submetidas a diferentes tipos de manejo. 1. Produção e densidade de perfilhos e de matéria seca. Pesqu. Agropec. Bras., v.27, p.131-142, 1992.

DEVASENA, B.; KRISHNA, N.; PRASAD, J.R. et al. Effect of stage of growth on chemical composition and in sacco dry matter degradability of colonial grass. Indian J. Anim. Sci., v.64, p.1108-1110, 1994. 
EZEQUIEL, J.M.B.; FAVORETTO, V. Efeito do manejo sobre a produção e composição química de perfilhos do capim-colonião (Panicum maximum Jacq.). Rev. Bras. Zootec., v.29, p.1596-1607, 2000.

FRANCE, J.; DHANOA, M.S.; THEODOROU, M.K. et al. A model to interpret gas accumulation profiles associated with in vitro degradation of ruminant feeds. J. Theor. Biol., v.163, p.99-111, 1993.

GERDES, L.; WERNER, J.C.; COLOZZA, M.T. et al. Características morfológicas, agronômicas e de valor nutritivo no período de estabelecimento das gramíneas forrageiras Marandu, Setária e Tanzânia. Bol. Ind. Anim., v.59, p.147-155, 2002.

GERDES, L.; WERNER, J.C.; COLOZZA, M.T. et al. Avaliação de características agronômicas e morfológicas das gramíneas forrageiras marandu, setaria e tanzânia aos 35 dias de crescimento nas estações do ano. Rev. Bras. Zootec., v.29, p.947954, 2000.

GIGER-REVERDIN，S. Review of the main methods of cell wall estimation: interest and limits for ruminants. Anim. Feed Sci. Technol., v.55, p.295-334, 1995.

GOERING, H.K.E, VAN, SOEST, P.J. Forages fiber analysis. Washington DC: Agricultural Research Service, USDA, 1970. 20p. (Handbook, 379).

GOMIDE, J.A.; ZAGO, C.P. Crescimento e recuperação do capim-colonião após o corte. Rev. Soc. Bras. Zootec., v.9, p.293-305, 1980.

GUIMARÃES JR, R.; GONÇALVES, L.C.; MAURÍCIO, R.M. et al. Cinética ruminal de silagens de milheto. Arq. Bras. Med. Vet. Zootec., v.60, p.1174-1180, 2008.

HARRISON, J.H.; BLAUWIEKEL, R.; STOKES, M.R. Fermentation and utilization of grass silage. J. Dairy Sci., v.77, p.3209-3235, 1994.

HENDERSON, N. Silage additives. Anim. Feed Sci. Technol., v.45, p.35-56, 1993.

JANK, L.; CALIXTO, S.; COSTA, J.C.G. et al. Catálogo de caracterização e avaliação de germoplasma de Panicum maximum: descrição morfológica e comportamento agronômico. Campo Grande: Embrapa-CNPGC, 1997. 53p. (Documentos, 68).
JUNG, H.G. Forage lignins and their effects on fiber digestibility. Agron. J., v.81, p.33-38, 1989.

JUNG, H.G.; ALLEN, M.S.Characteristics of plant cell walls affecting intake and digestibility of forages by ruminants. J. Anim. Sci., v.73, p.2774-2790, 1995.

MAURICIO, R.M.; MOULD, F.L.; DHANOA, M.S. et al. A semi-automated in vitro gas production technique for ruminants feedstuff evaluation. Anim. Feed Sci. Technol., v.79, p.321-330, 1999.

MAURÍCIO, R.M.; PEREIRA, L.G.R.; GONÇALVES, L.C. et al. Relação entre pressão e volume para implantação da técnica in vitro semiautomática de produção de gases na avaliação de forragens tropicais. Arq. Bras. Med. Vet. Zootec., v.55, p.216-219, 2003.

McDONALD, P.; HENDERSON, A. R.; HERON, S. The biochemistry of silage. 2.ed. Marlow: Chalcombe Publications, 1991. 340p.

MOORE, K.J.; HATFIELD, R.D. Carbohydrates and forage quality. In: FAHEY JR, G.C. (Ed). Forage quality, evaluation, and utilization. Lincoln: University of Nebraska, 1994. cap.6, p.229-280.

OFFICIAL methods of analysis. 16.ed. Washington DC: AOAC, 1995.

ØRSKOV, E.R. Trails and trails in livestock research. Abeerden: Garamond, 2002. 204p.

PACIULLO, D.S.C. Características anatômicas relacionadas ao valor nutritivo de gramíneas forrageiras. Ciênc. Rural, v.32, p.357-364, 2002.

PACIULLO, D.S.C.; GOMIDE, J.A.; SILVA, E.A.M. Degradação in vitro de tecidos da lamina foliar e do colmo de gramíneas forrageiras tropicais, em função do estádio de desenvolvimento. Rev. Bras. Zootec., v.31, p.900-907, 2002.

PEDREIRA, J.V. Crescimento estacional dos capins colonião (Panicum maximum Jacq.), gordura (Melinis minutiflora Pal de Beauv), jaraguá (Hyparrhenia rufa (Ness) Stapf) $e$ pangola de Taiwan A-24 (Digitaria pentzii Stent), 1972. 61f. Dissertação (Mestrado) Escola Superior de Agricultura "Luiz de Queiroz", Universidade de São Paulo, Piracicaba. 
SANTOS, P.M.; CORSI, M.; BALSALOBRE, M.A. Efeito da frequência de pastejo e da época do ano sobre a produção e a qualidade em Panicum maximum cvs. Tanzânia e Mombaça. Rev. Bras. Zootec., v.28, p.244-249, 1999.

SNIFFEN, C.J.; O`CONNOR, J.D.; VAN SOEST, P.J. A net carbohydrate and protein system for evaluating cattle diets: II. Carbohydrate and protein availability. J. Anim. Sci., v.70, p.3562-3577, 1992.

THEODOROU, M.K.; WILLIANS, B.A.; DHANOA, M.S. et al. A simple gas production method using pressure transducer to determine the fermentation kinetics of ruminant feeds. Anim. Feed Sci. Technol., v.48, p.185-197, 1994.

VALADARES FILHO, S.C.; MAGALHAES, K.A.; ROCHA JR, V.R. et al. Tabelas brasileiras de composição de alimentos para bovinos. 2.ed. Viçosa: UFV, 2006, 329p.
VAN SOEST, P.J. Nutritional ecology of the ruminant. 2.ed. Ithaca: Cornell University, 1994. 476p.

VAN SOEST, P.J., ROBERTSON, J.B., LEWIS, B.A. Official for dietary fiber, neutral detergent fiber and nonstarch polysaccharides in relation to animal nutrition. J. Dairy Sci., v.74, p.35833597, 1991.

WILLIAMS, B.A. Cumulative gas production: how to measure it, and what it can (not) tell you. In: ISNH6 SATELLITE WORKSHOP/SYMPOSIUM WILD AND DOMESTIC HERBIVORE DIET CHARACTERIZATION, 2003, Mexico. Proccedings ... Mexico: UADY, 2003. p.1-3.

WILSON, J.R.; HATFIELD, R.D. Structural and chemical changes of cell wall types during stem development: consequences for fibre degradation by rumen microflora. Austr. J. Agric. Res., v.48, p.165-180, 1997. 